\title{
OPTIMIZING AIR VELOCITY FOR THE UNDERFLOOR FORCED VENTILATION TO PROTECT A REFRIGERATED WAREHOUSE FROM FROST HEAVING
}

\author{
Jingfu $\mathrm{Jia}^{1^{*}}-$ Manjin Hao $^{2}-$ Jianhua Zhao $^{1}$ \\ ${ }^{1}$ Ocean College of Hebei Agricultural University, Qinhuangdao 066003, Hebei, China \\ ${ }^{2}$ School of Architecture \& Mechanics, Yanshan University, Qinhuangdao 066004, Hebei, China
}

\begin{tabular}{l} 
ARTICLE INFO \\
\hline Article history: \\
Received: 14.04 .2016$. \\
Received in revised form: 09.10.2016. \\
Accepted: 03.11 .2016$. \\
\hline Keywords: \\
Refrigerated warehouse floor \\
Forced ventilation \\
Frost heave protection \\
Steady three-dimensional heat transfer \\
Heat transfer performance \\
Air velocity
\end{tabular}

DOI: https://doi.org/10.30765/er.38.3.9

\section{Introduction}

Refrigerated warehouse can provide suitable humidity and low temperature environment for food, so it has been an important part of food cold chain. At present, it has been widely used in food products factory, dairy factory, hotel, supermarket, and other departments. It is mainly used for the constant temperature storage and frozen processing of food such as dairy products, meat, aquatic products, poultry, fruits and vegetables, cold drink, and so on. Because the refrigerated warehouse is at low temperature environment for years, moisture in the base soil is liable to be frozen. Once the soil is frozen, the volume then would expand. This would cause the ground fracture and the entire building structure to deform. The seriously frozen would result in refrigerated warehouse not being used. Therefore, in addition to adding effective insulating layer to refrigerated warehouse floor, some frost heave protection measures must also be taken. By doing so,

\begin{abstract}
:
Forced or natural ventilation is the most common measure of frost heave protection for refrigerated warehouse floor. To optimize air velocity for the underfloor forced ventilation system of refrigerated warehouse, a steady state threedimensional mathematical model of heat transfer is set up in this paper. The temperature fields of this system are simulated and calculated by CFD software PHOENICS under different air velocity, $1.5 \mathrm{~m} / \mathrm{s}, 2.5 \mathrm{~m} / \mathrm{s}$ or $3.5 \mathrm{~m} / \mathrm{s}$. The results show that the optimized air velocity is $1.5 \mathrm{~m} / \mathrm{s}$ when the tube spacing is $1.5 \mathrm{~m}$.
\end{abstract}

the base soil could be maintained at a temperature above $0^{\circ} \mathrm{C}$ [1-3], and it wouldn't freeze.

Several commonly used frost heave protection measures consist of electrical heating, pumping of warming liquids, forced or natural ventilation, etc. Electrical heating measure of frost heave protection refers to burying electric heating wire mesh in concrete cushion under the floor insulation layer, and supplying power to electric heating wire mesh on time. However, it would consume lots of electricity, and must be strictly protected from short circuit. Pumping of warming liquids measure means embedding liquid pipelines in concrete cushion under the floor insulation layer, supplying heated liquid to pipelines and circulating them by pump. However, large quantity of liquid pipelines should be used in this system, and the hidden danger of corrosion leakage in the connection place should not be ignored. Forced or natural ventilation measure refers to burying air tubes in concrete cushion under the floor insulation layer and supplying heat by forced or

\footnotetext{
* Corresponding author. Tel.: +86 3353150030

E-mail address: jjf0369@163.com.
} 
natural ventilation. Floor without hidden danger from safety is the most common measure of frost heave protection. Due to the stable air velocity, the effect of forced ventilation measure is better than of natural ventilation. To facilitate centralized management, fans are placed in ventilator room nearby the refrigerating station. The schematic diagram of the overall ventilation system is shown in Fig. 1.

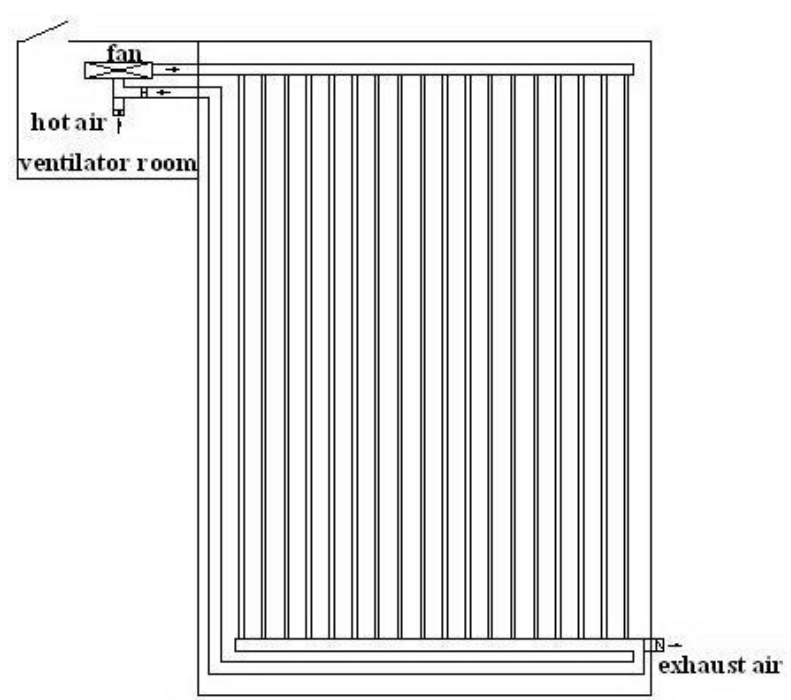

Figure 1. The schematic diagram of the overall ventilation system.

Some empirical values are often used to design and construct refrigerated warehouse floor ventilation system of frost heave protection for years. Deeper researches on this system are not widely known, unless studied from Zukun GAO and Ran ZHOU et al $[4,5]$. So a systematic research is of practical significance to direct design, construction, and better operation..

To optimize air velocity for the underfloor forced ventilation system of refrigerated warehouse, a steady state three-dimensional mathematical model of heat transfer is set up in this paper. The heattransfer model is simplified reasonably, and the calculation conditions are defined according to the heat-transfer process. The temperature fields of this system are simulated and calculated by CFD software PHOENICS under different air velocity, $1.5 \mathrm{~m} / \mathrm{s}$, $2.5 \mathrm{~m} / \mathrm{s}$ or $3.5 \mathrm{~m} / \mathrm{s}$.

\section{Materials and methods}

\subsection{An arithmetic element of heat-transfer model}

A tiny part of the cold storage room floor and soil layer of refrigerated warehouse is picked out and used as an arithmetic element of the heat-transfer model, as shown in Fig. 2. The size of the model is defined as $X^{*} Y^{*} Z=1500 \mathrm{~mm} * 3900 \mathrm{~mm}^{*} 1000 \mathrm{~mm}$. The top-down structure layers of the refrigerated warehouse floor are [6]: reinforced concrete surface course, cement mortar protection course, asphalt felt damp-proof course, rigid polyurethane foam heat insulating layer, asphalt felts vapor barrier, cement mortar leveling course, precast concrete board, medium sand packing layer(buried concrete ventilation tube within). A soil layer is below structure layers of floor.

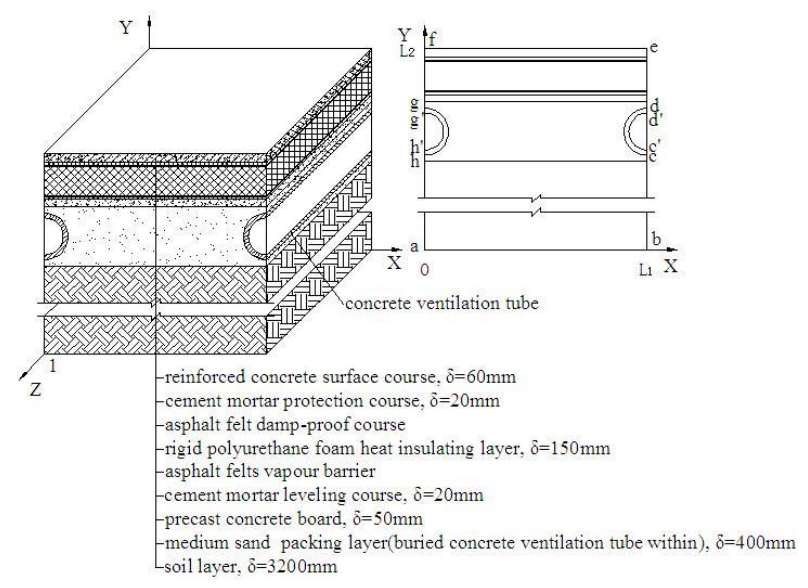

Figure 2. The calculating element of heat-transfer model for refrigerated warehouse floor.

\subsection{Model assumptions}

The heat transfer process of the refrigerated warehouse floor is very complex in fact. In order to facilitate solving and analyzing, the heat-transfer model is simplified and assumed reasonably. These assumptions are as follows [7-13]: Firstly, the heat transfer process of the refrigerated warehouse floor is assumed to be a steady state heat three-dimensional conduction process. Secondly, the materials in the same structural layer of the floor are assumed to be homogeneous, isotropic, and with constant physical properties. Lastly, the thermal contact resistance between each layer, the thermal resistance of the asphalt felt layer, and the moisture transfer are all assumed to be negligible.

\subsection{Equation and boundary conditions}

The research object is the cold storage room floor of refrigerated warehouse in Tianjin area of China in winter.. There is no heat source in the refrigerated warehouse floor, so the steady state three- 
dimensional differential equation of heat conduction of the arithmetic element of the heat-transfer model may be described as following:

$$
\frac{\partial^{2} t}{\partial x^{2}}+\frac{\partial^{2} t}{\partial y^{2}}+\frac{\partial^{2} t}{\partial z^{2}}=0
$$

The boundary conditions of the arithmetic element are defined as following:

The design temperature of the cold storage room floor is defined as: $t_{n}=-20^{\circ} \mathrm{C}$. There are fan blowers in the cold storage room, therefore the heat convective coefficient of the upper surface of the cold storage room floor is defined as: $\alpha_{n}=12 \mathrm{~W} /\left(\mathrm{m}^{\wedge} 2 \cdot{ }^{\circ} \mathrm{C}\right)$ [14]. So the boundary condition of the upper surface of the cold storage room floor is:

$$
-\left.\lambda \frac{\partial t}{\partial y}\right|_{y=L_{2}}=\alpha_{n}\left(t_{n}-t_{n b}\right)=12 \times\left(-20-t_{n b}\right)
$$

where, $\lambda$ is the heat conduction coefficient of each kind of material $\left(\mathrm{W} /\left(\mathrm{m} \cdot{ }^{\circ} \mathrm{C}\right)\right), t_{n b}$ is the temperature of the upper surface of the cold storage room floor $\left({ }^{\circ} \mathrm{C}\right)$.

The soil temperature is defined as: $t_{s}=10.4{ }^{\circ} \mathrm{C}$. The soil temperature is derived from the minimum mean soil temperature of $3.2 \mathrm{~m}$ deep in Tianjin city during the months of March and April, over the years [1]. So the boundary condition of the lower surface of the heat-transfer model is:

$$
\left.t\right|_{y=0}=t_{s}=10.4
$$

In the refrigerated warehouse floor, ventilation tubes are symmetrically placed in terms of certain spacing in X-direction, so in the arithmetic element, as shown in Fig. 2, two boundary surfaces of the model in Xdirection are approximately seemed as adiabatic surfaces and the boundaries are:

$$
\left.\frac{\partial t}{\partial x}\right|_{x=0}=\left.\frac{\partial t}{\partial x}\right|_{x=L_{1}}=0
$$

Similarly, the two boundary surfaces of the model in Z-direction are also approximately seemed as adiabatic surfaces and the boundaries are:

$$
\left.\frac{\partial t}{\partial z}\right|_{z=0}=\left.\frac{\partial t}{\partial z}\right|_{z=1}=0
$$

Where $x, y \in c^{\wedge} d, g^{\wedge} h, z \in(0,1)$.

The supply air temperature in ventilation tubes of the refrigerated warehouse floor is defined as: $t_{i n}=10^{\circ} \mathrm{C}$. The inner diameter and outer diameter are:

$d_{1}=250 \mathrm{~mm}, d_{2}=316 \mathrm{~mm}$. The boundary condition of outer surface of ventilation tube is:

$$
t=t_{w 2}=t_{f}+\frac{V \cdot \rho \cdot c_{p} \cdot\left(t_{\text {out }}-t_{\text {in }}\right)}{K \cdot l}\left(1+\frac{1}{2 \pi \lambda} \ln \frac{d_{2}}{d_{1}} \cdot K \cdot l\right)
$$

where, $t_{w 2}$ is the temperature of the outer surface of ventilation tube $\left({ }^{\circ} \mathrm{C}\right), t_{f}=\frac{t_{\text {in }}+t_{\text {out }}}{2}$ is mean air temperature of ventilation tube $\left({ }^{\circ} \mathrm{C}\right), V$ is the air flow of the system $\left(\mathrm{m}^{\wedge} 3 / \mathrm{s}\right), \rho$ is the air density $\left(\mathrm{kg} / \mathrm{m}^{\wedge} 3\right), c_{p}$ is specific heat at constant pressure of $\operatorname{air}\left(\mathrm{J} /\left(\mathrm{kg} \cdot{ }^{\circ} \mathrm{C}\right)\right), t_{\text {out }}$ is the mean temperature of air at outlet of the system $\left({ }^{\circ} \mathrm{C}\right), K$ is the coefficient of heat-transfer between air and tube wall in ventilation tube on unit length $\left(\mathrm{W} /\left(\mathrm{m}^{\circ}{ }^{\circ} \mathrm{C}\right)\right), l$ is total length of ventilation tube $(\mathrm{m})$.

\section{The results and discussion}

\subsection{Simulation results of the heat-transfer model}

When the ventilation system is running under different air velocity, $1.5 \mathrm{~m} / \mathrm{s}, 2.5 \mathrm{~m} / \mathrm{s}$ or $3.5 \mathrm{~m} / \mathrm{s}$, and tube spacing is $1.5 \mathrm{~m}$, and the other simulation conditions are not changed, numerical simulations of the heat-transfer model of the refrigerated warehouse floor are performed using CFD software PHOENICS. The obtained temperature fields of XY section of the refrigerated warehouse floor model in each case are shown in Fig. 3, Fig. 4 and Fig. 5. While air velocity is $3.5 \mathrm{~m} / \mathrm{s}$, the temperature fields of upper, middle and lower surface for heating layer are shown in Fig. 6, Fig. 7 and Fig. 8. The temperature distribution curves of points at $\mathrm{Z}=1 \mathrm{~m}$ on upper, middle and lower surface for heating layer in each case are shown in Fig. 9, Fig. 10 and Fig. 11. The temperature distribution curves of points at $\mathrm{Z}=1 \mathrm{~m}$ on lower surface for heating layer in each case are shown in Fig. 12. 

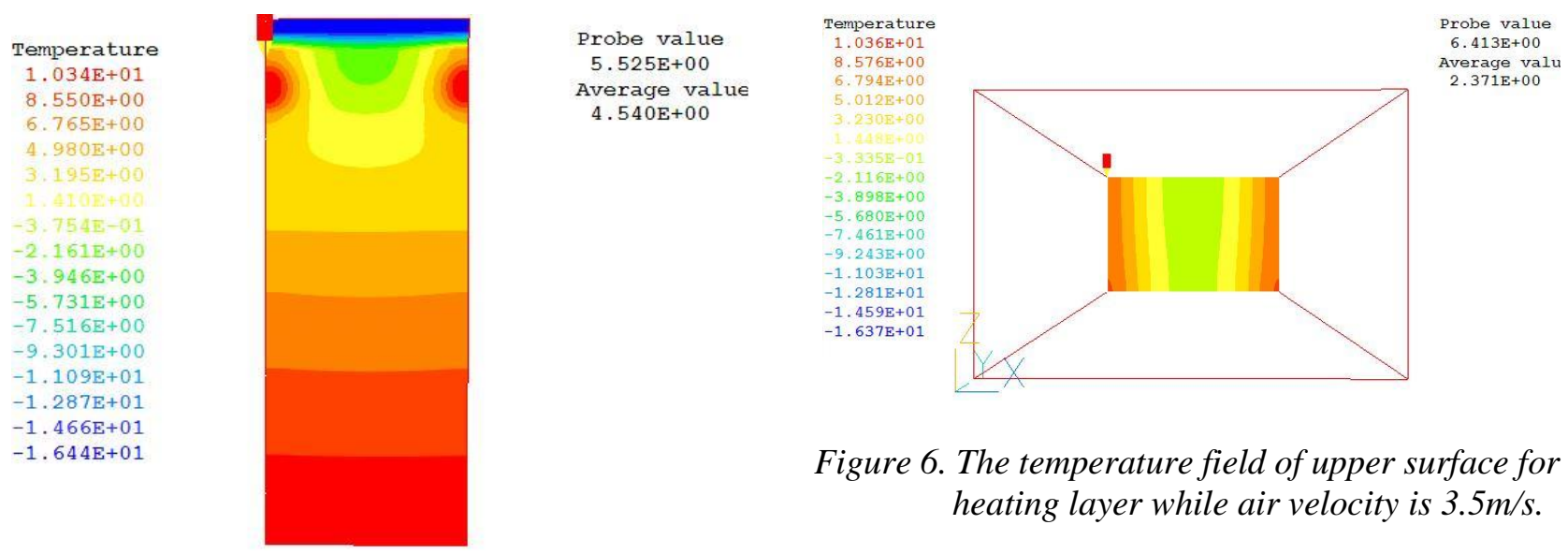

Figure 3. The temperature field of $X Y$ section of refrigerated warehouse floor while air velocity is $1.5 \mathrm{~m} / \mathrm{s}$.
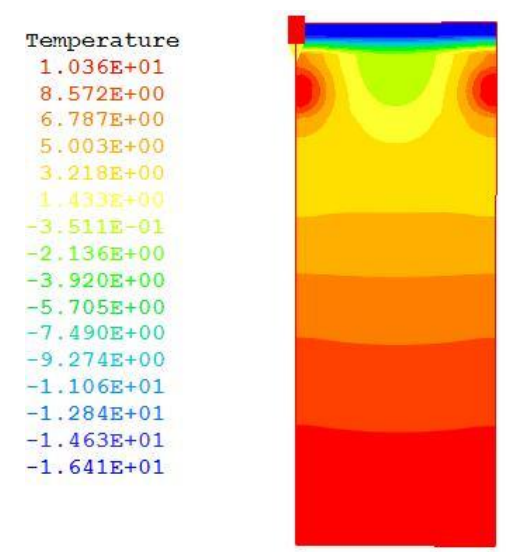
Probe value $6.321 \mathrm{E}+00$ Average value $5.124 \mathrm{E}+00$

Figure 4. The temperature field of XY section of refrigerated warehouse floor while air velocity is $2.5 \mathrm{~m} / \mathrm{s}$.

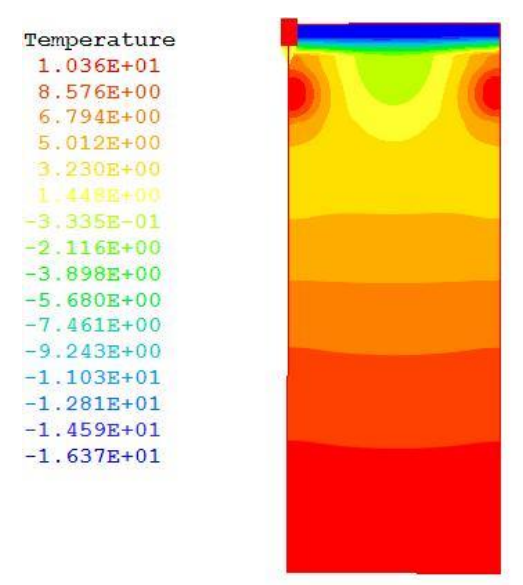

Figure 5. The temperature field of $X Y$ section of refrigerated warehouse floor while air velocity is $3.5 \mathrm{~m} / \mathrm{s}$.
Figure 6. The temperature field of upper surface for heating layer while air velocity is $3.5 \mathrm{~m} / \mathrm{s}$.

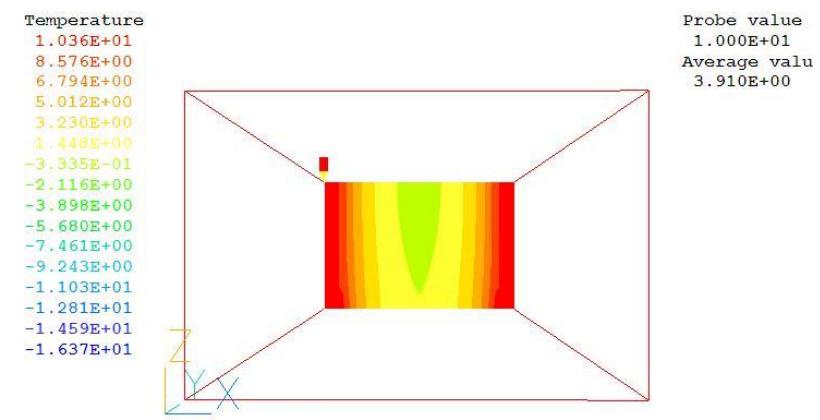

Figure 7. The temperature field of middle surface for heating layer while air velocity is $3.5 \mathrm{~m} / \mathrm{s}$.

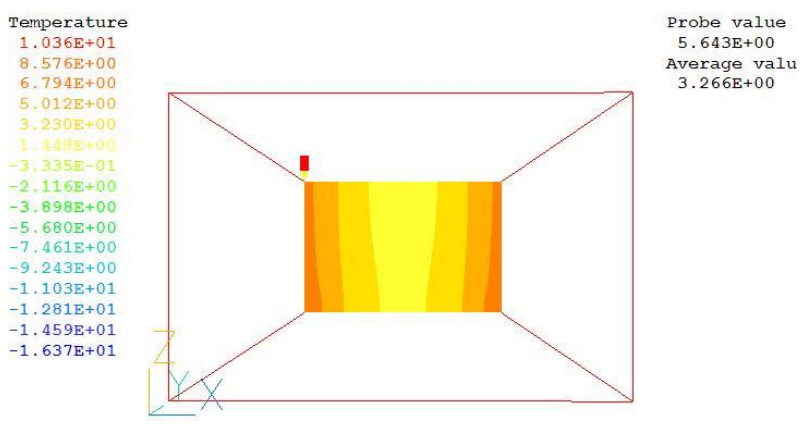

Figure 8. The temperature field of lower surface for heating layer while air velocity is $3.5 \mathrm{~m} / \mathrm{s}$.

When underfloor forced ventilation system is running and air velocity is $1.5 \mathrm{~m} / \mathrm{s}$, the obtained numerical results are shown in Fig. 3, Fig. 9 and Fig. 12. The average temperature of the upper surface of heating layer is $1.290^{\circ} \mathrm{C}$. The average temperature of the lower surface of heating layer is $2.322^{\circ} \mathrm{C}$. The temperature fluctuation amplitudes of each point at $\mathrm{Z}=1 \mathrm{~m}$ on upper surface of heat layer are $7.723^{\circ} \mathrm{C}$ (from -2.186 to $5.537^{\circ} \mathrm{C}$ ). 


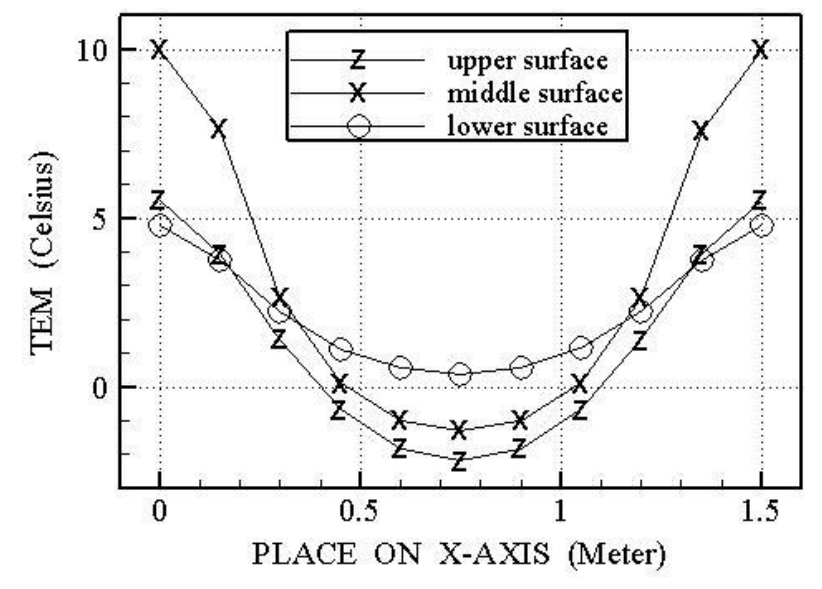

Figure 9. The temperature curves of points on upper, middle, and lower surface for heating layer while air velocity is $1.5 \mathrm{~m} / \mathrm{s}$.

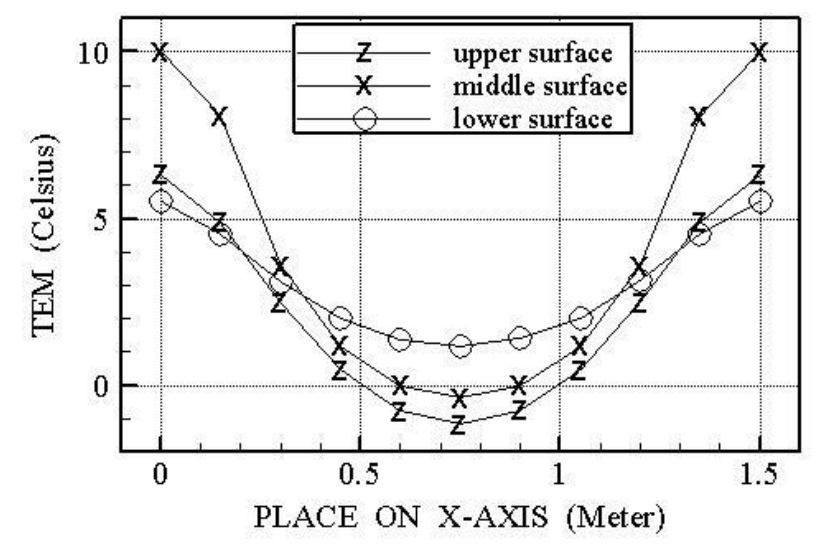

Figure 10. The temperature curves of points on upper, middle, and lower surface for heating layer while air velocity is $2.5 \mathrm{~m} / \mathrm{s}$.

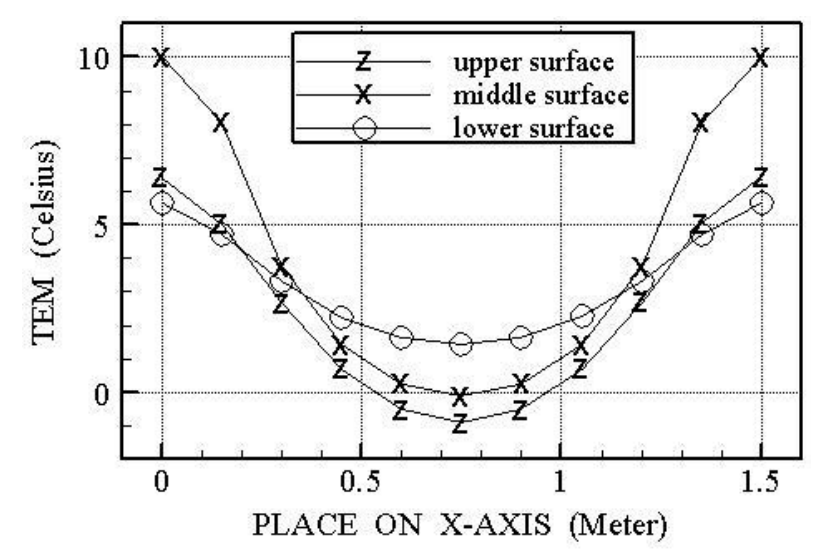

Figure 11. The temperature curves of points on upper, middle, and lower surface for heating layer while air velocity is $3.5 \mathrm{~m} / \mathrm{s}$.

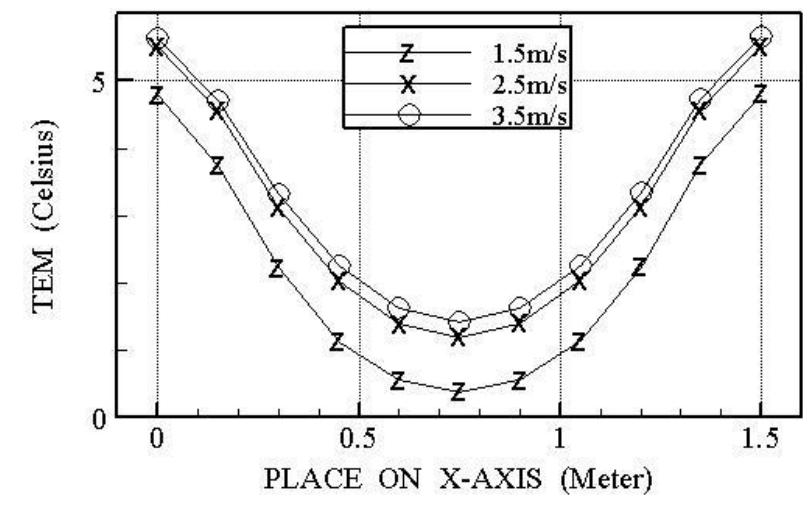

Figure 12. The temperature curves of points on lower surface for heating layer while air velocity is $1.5 \mathrm{~m} / \mathrm{s}, 2.5 \mathrm{~m} / \mathrm{s}$ and $3.5 \mathrm{~m} / \mathrm{s}$.

The temperature fluctuation amplitudes of each point at $\mathrm{Z}=1 \mathrm{~m}$ on lower surface of heat layer are $4.424^{\circ} \mathrm{C}$ (from 0.387 to $4.811^{\circ} \mathrm{C}$ ). The average temperature of the section at $\mathrm{Z}=1 \mathrm{~m}$ is $4.54^{\circ} \mathrm{C}$.

When underfloor forced ventilation system is running, and air velocity is $2.5 \mathrm{~m} / \mathrm{s}$, the obtained numerical results are shown in Fig. 4, Fig. 10 and Fig. 12. The average temperature of the upper surface of heating layer is $2.190^{\circ} \mathrm{C}$. The average temperature of the lower surface of heating layer is $3.077^{\circ} \mathrm{C}$. The temperature fluctuation amplitudes of each point at $\mathrm{Z}=1 \mathrm{~m}$ on upper surface of heat layer are $7.499^{\circ} \mathrm{C}$ (from -1.164 to $6.335^{\circ} \mathrm{C}$ ). The temperature fluctuation amplitudes of each point at $\mathrm{Z}=1 \mathrm{~m}$ on lower surface of heat layer are $4.330^{\circ} \mathrm{C}$ (from 1.187 to $5.517^{\circ} \mathrm{C}$ ). The average temperature of the section at $\mathrm{Z}=1 \mathrm{~m}$ is $5.124^{\circ} \mathrm{C}$.

When underfloor forced ventilation system is running and air velocity is $3.5 \mathrm{~m} / \mathrm{s}$, the obtained numerical results are shown in Fig. 5, Fig. 6, Fig. 7, Fig. 8, Fig. 11 and Fig. 12. The average temperature of the upper surface of heating layer is $2.371{ }^{\circ} \mathrm{C}$. The average temperature of the lower surface of heating layer is $3.266^{\circ} \mathrm{C}$. The temperature fluctuation amplitudes of each point at $\mathrm{Z}=1 \mathrm{~m}$ on upper surface of heat layer are $7.338^{\circ} \mathrm{C}$ (from -0.912 to $6.426^{\circ} \mathrm{C}$ ). The temperature fluctuation amplitudes of each point at $\mathrm{Z}=1 \mathrm{~m}$ on lower surface of heat layer are $4.234^{\circ} \mathrm{C}$ (from 1.418 to $5.652^{\circ} \mathrm{C}$ ). The average temperature of the section at $\mathrm{Z}=1 \mathrm{~m}$ is $5.242^{\circ} \mathrm{C}$.

\subsection{Numerical results analysis}

In terms of the obtained temperature distribution figures shown in Fig. 3 to Fig. 12, the numerical results are discussed. In each model, the temperatures 
of each point on lower surface of heat layer are more uniform, and the temperature fluctuation amplitude is smaller than which of points on upper and middle surface. The closer the distance to the tube center is, the temperatures of each point on the upper, middle, and lower surface of the heat layer are higher.

When air velocity is larger, the temperature fluctuation amplitudes of points on the upper and lower surface of heating layer are both smaller, and the average temperatures of the upper and lower surfaces are both higher. If air velocity is enlarged, the heat convective coefficient of the inner surface of pipe would increase, and the heat exchange capacity would enhance. Therefore, when air velocity is larger, the heat exchange amount is larger, too, and the cold energy transferred from refrigerated warehouse floor to soil layer would be substantially reduced. For the higher temperature of the lower surface of heating layer, the moisture of soil can effectively prevent from freezing. So the refrigerated warehouse floor can refrain from frost heaving. However, accompanied by the increase of air velocity, the heat exchange capacity of tube would not infinitely enhance. According to the numerical results, the difference of heat exchange capacity of tube is inconspicuous when air velocity is respectively $2.5 \mathrm{~m} / \mathrm{s}$ and $3.5 \mathrm{~m} / \mathrm{s}$.

\section{Conclusion}

Based on the developed model of refrigerated warehouse floor, by performing numerical simulations and analyzing the obtained temperature distributions, conclusions are summarized as following:

When the ventilation system is running under different air velocity, $1.5 \mathrm{~m} / \mathrm{s}, 2.5 \mathrm{~m} / \mathrm{s}$ or $3.5 \mathrm{~m} / \mathrm{s}$, and tube spacing is consistently $1.5 \mathrm{~m}$, the average temperature of the lower surface of heating layer in each case will be always above $0^{\circ} \mathrm{C}$, and the soil under heating layer will not be frozen for ever. The effectiveness of frost heave protection in each case is better.

The air velocity has certain influence on the temperature distributions of heating layer of the refrigerated warehouse floor. However, when air velocity increases to a certain extent, the influence of it on the heat transfer performance of floor is obviously weakened.

When other simulation conditions are not changed, the larger air velocity is, the better effectiveness of frost heave protection there is. But the larger air velocity may cause the temperature of heating layer to increase. The cold load of refrigerated warehouse will increase accordingly, too. This will lead to more serious waste of energy. At the same time, the storage quality of cargos near the refrigerated warehouse floor will be affected. Chibin YU [6] pointed out that better average temperature of the heating layer is between $1{ }^{\circ} \mathrm{C}$ and $2^{\circ} \mathrm{C}$. Therefore, based on the simulation conditions and calculated results of this paper, when the tube spacing is $1.5 \mathrm{~m}$, the optimized air velocity is $1.5 \mathrm{~m} / \mathrm{s}$.

\section{References}

[1] SBIT: Code for design of cold store, China Planning Press, Beijing, 2001.

[2] RPEAOMC: Refrigeration technology for cold storage, China Financial and Economic Publishing House, Beijing, 1980.

[3] Tan, X.D.: Cold storage construction, China Light Industry Press, Beijing, 2006.

[4] Gao, Z.K.: Heat transfer calculation of the cold store mechanically ventilated for preventing the ground from frost heaving, Heating Ventilation \& Air Conditioning, 26 (1996) 4, 68-71.

[5] Zhou, R. et al: Numerical simulation of temperature field of cold storage ventilation ground structure layer, Cold Storage Technology, 30 (2007) 4, 37-40.

[6] Yu, C.B.: Practical handbook of refrigeration and air-Conditioning engineering, China Machine Press, Beijing, 2001.

[7] Jia, J.F., He, W.: Effect of Ventilation Tube Diameter on Thermal Performance of Food Refrigerated Warehouse Floor Antifreezing Mechanical Ventilation System, Advance Journal of Food Science and Technology, 7 (2015) 5, 320-325.

[8] Li, H.M., Jin, W.L.: Temperature field simulation of building envelops, Journal of Building Structures, 25 (2004) 6, 93-98.

[9] Tsilingiris, P.T.: Thermal flywheel effects on the time varying conduction heat transfer through structural walls, Energy and Buildings, 35 (2003) 10, 1037-1047.

[10] Jia, J.F., He, W.: Effect of thickness of heat insulating material in bulkhead on cabin temperature of reefer ship for agricultural products, Journal of Chemical and Pharmaceutical Research, 5 (2013) 11, 403-408.

[11] Sui, X.M., Han, G.H., Chen, F.: Numerical simulation on air distribution of a tennis hall in winter and evaluation on indoor thermal 
environment, Engineering Review, 34 (2014) 2, 109-118.

[12] Wang, H.X.: Technical requirements and measures of energy-saving insulation wall, Energy Conservation Technology, 3 (2002), 3637.
[13] Lv, Z.: Analysis on the advantages and disadvantages of several kinds of building external wall thermal insulation technology, Jiangsu Building Materials, 26 (2006), 40-42.

[14] Li, J.H., Wang, C.: Refrigerating house design, China Machine Press, Beijing, 2003. 